\title{
The Application of Multi-level Fuzzy Evaluation System in Urban Sustainable Development
}

\author{
Ruiwei Feng ${ }^{1, \text { a }}$ \\ ${ }^{1}$ School of North China Electricity Power University, North China Electricity Power University, \\ Baoding 071000, China. \\ a736586335@qq.com
}

\begin{abstract}
As the world urbanizing rapidly, the task of achieving smart growth in cities is becoming even more important. In this paper, we will propose a "Smart Growth Coefficient"(SGC) and analyze it by Multi-level Fuzzy Evaluation System. We first define SGC to measure the extent to which the growth plan of a certain city is accordant with the principles of smart growth. The greater the SGC, the better the accordance. Dividing the city into multiple uniform grids(Gridding), we grade each index in the indicator layer. For one certain index, the ratio of the number of grids graded a certain score ( $\mathrm{Vi}$ ) to the total number of grids is defined as the membership degree to which the index can be graded as the score of the criterion layer in the evaluation system of SGC. Using this method, we get the univariate fuzzy evaluation matrix. Then we construct the membership function for each index. After that, the weights and the evaluation matrix are combined together to make a comprehensive evaluation to give the value of SGC in the target layer.
\end{abstract}

Keywords: Smart growth coefficient, multi-level fuzzy evaluation system, gridding, membership function.

\section{Introduction}

At present, there are many models and studies related to smart growth. For example: Transect Planning[1], UGB(urban growth boundary) planning theory[2]. By determining the main landscape features of the ecological belt and using the spatial allocation of land use, we can adjust the heterogeneous landscape. Finally, control of low-density urban development model and protect agricultural land and ecological land.

UGB is the expected growth frontier of a city. Within the boundary is the current boundary and reserved land[3]. Outside the border is an agricultural land, prohibiting urban development. We hope to get a model to measure the success of a city's plan and propose a better growth plan. In our expectations, this model helps the relevant departments to identify problems as soon as possible, to take measures and to achieve the goal of three E's.

\section{Method and Results}

Select two mid-sized cities (any city with a population of between 100,000 and 500,000 persons), on two different continents as our research objects.

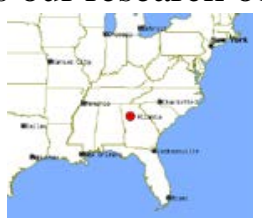

Fig.1 Atlanta:

Georgia, United States

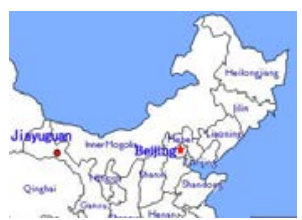

Jiayuguan:

Northwest of Gansu Province, China

\subsection{Terms, Definitions and Symbols}

\section{- $z$ Smart Growth Coefficient}

We define it to measure the degree of coincidence of urban planning to smart growth.

- $r_{i j}$ Membership degree

- $U_{i}$ Criterion layer element

- $U_{i j}$ Each index of $U_{i}$

- A Weight vectors of three criterion.

(Economic criterion $U_{1}$, Social criterion $U_{2}$ and Environmental criterion $U_{3}$.) 


\subsection{Assumptions}

- We assume the SGC as a coefficient of the city by GDP per capita[4], local fiscal revenue, number of tourist attractions, per capita housing area, natural population growth rate, employment rate and job housing balance index, green coverage rate, land utilization degree of the mixed effects, ignoring the influence of other factors.

- Assuming that the SGC of Atlanta is directly proportional to the natural growth rate of population, while Jiayuguan is opposite. SGC of the each is inversely proportional to per capita housing area, and proportional to the remaining eight indexes.

- We assume that the regional boundaries of these two cities are extremely desirable, that is, the urban boundary envelope is a relatively regular geometric figure.

- We assume that there is only a flat mix of land use: including the city's organic mixed industries, farmland, green space, residential and public facilities, etc. without considering the vertical mixing. And we assume the compact building design is a high-rise building.

\subsection{The Model}

\section{$>$ Determine Multi-Level Fuzzy Evaluation indexes}

The influencing factors of SGC in different cities are changeable and complicated. For the convenience of discussion, we consider the three E's of sustainability and the 10 principles of smart growth and use the method of Multi-Level Fuzzy Evaluation to set up a comprehensive evaluation system as follows[5]:

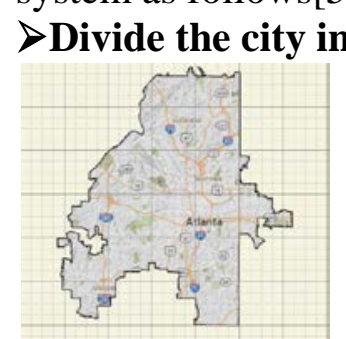

Fig.2 Borderline Shape Graphics of Atlanta and Jiayuguan
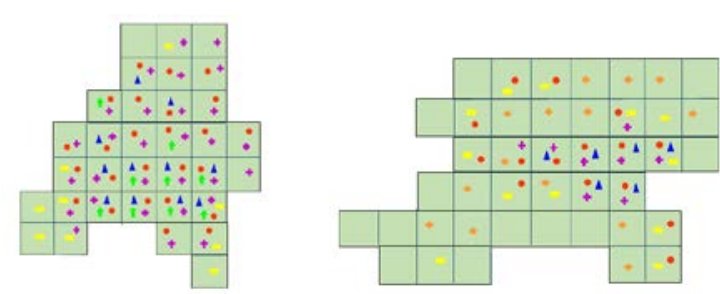

Fig.3 Ideal city graphics of Atlanta and Jiayuguan

*Note: $\triangle$ Commercial land $\odot$ Residential land $\diamond$ Farmland $\square$ Heavy industrial land

Public facilities land (parks, schools, green spaces, parking lots, etc.)

$>$ Establish the evaluation set of comprehensive evaluation

In evaluating the sustainable development of the city, we divide it into five levels. Here, we put them as "10 points", "points", "6 points", "4 points", "2 points" and "10 points" is the highest level.

Comment set as: $\boldsymbol{V}=\{10$ points ,8points ,6points,4points ,2points $\}$;

\section{$>$ Determining weight}

The importance of the three criteria and 10 indexes are different in the comprehensive evaluation. So we give them different weights by Analytic Hierarchy Process.

The weight vector is: $\mathrm{A}=\left(a_{1}, a_{2}, a_{3}\right), \mathrm{A}_{i}=\left(a_{i 1}, a_{i 2}, \ldots\right), \quad i=1,2,3$

A represents the weight of three criteria, and $\mathrm{Ai}$ represents the weight vector of each index $\left(U_{i j}\right)$ in each criterion (Ui). Through data integration and expert evaluation, We judge the influence of three criteria on the target layer and construct a discriminant matrix. Then we solve the matrix to obtain the distribution of importance degree of three factors:

$$
\mathrm{D}=\left[\begin{array}{ccc}
\frac{1}{1} & 4 & 5 \\
\frac{1}{1} & 1 & 3 \\
\frac{1}{5} & \frac{1}{3} & 1
\end{array}\right], \mathrm{A}=\left\{\begin{array}{lll}
0.6738 & 0.2255 & 0.1007
\end{array}\right\} ;
$$

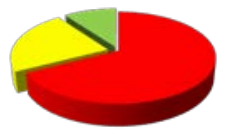

Fig.4 Importance of Criterion layer element

Judgment matrix and weight: 
$u_{1}$

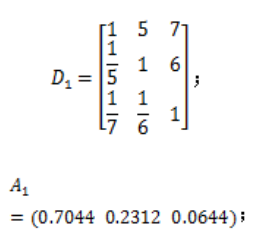

$u_{2}$

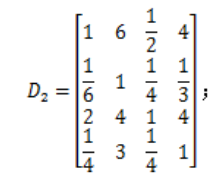

$\mathrm{A}_{2}$

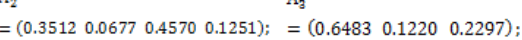

The weight of the criterion and index are summarized as follows:

Table 1 Importance of the criteria and indexes

\begin{tabular}{ccc|cccc|ccc}
\hline \multicolumn{3}{c|}{$a_{1}$} & \multicolumn{4}{c}{$a_{2}$} & \multicolumn{3}{c}{$a_{31}$} \\
\hline \multicolumn{3}{c|}{$\mathbf{0 . 6 7 3 8}$} & \multicolumn{4}{c|}{0.1007} \\
\hline$a_{11}$ & $a_{12}$ & $a_{13}$ & $a_{21}$ & $a_{22}$ & $a_{23}$ & $a_{21}$ & $a_{31}$ & $a_{31}$ & $a_{31}$ \\
\hline 0.7044 & 0.2312 & 0.0644 & 0.3512 & 0.0667 & 0.4570 & 0.1251 & 0.6483 & 0.1220 & 0.2297 \\
\hline
\end{tabular}

- Score the number of attractions of each grid:

Constructed membership function as follows:

$$
u_{\mathrm{A}}=\frac{k}{5}
$$

$k$ is the number of attractions contained in grid. If $k=1$, then $u_{\mathrm{A}}=0.2$. The grid is 2 points in this indicator. The rest of the indexes for each grid is similar to the grading method [6].

$>$ Determine the subordinate degree of each index

Take grids as the jury, and the number of grids at the level of a comment represents the number of votes obtained for this rating. For the sustainable development level of a city, the subordinate degree of a certain index belongs to the comment is as follows:

$$
r_{i j}=\frac{\mathrm{n}_{\mathrm{j}}}{\mathrm{n}}
$$

$\mathrm{n}_{\mathrm{j}}$ is the grid in the whole grid belongs to level $\mathrm{j}$; $\mathrm{n}$ is the total grid number;

For the 10 indexes in the index layer (C), we divide them into economic, social, and environmental categories in the (B). Under each criterion, construct the evaluation matrix. For the evaluation of the five levels of concentration, the $U_{1} \sim U_{3}$ has three evaluation matrix $R_{1} \sim R_{3}$..

$\operatorname{Atlanta}\left(R_{1 i}\right)$

$$
R_{11}=\frac{1}{34}\left[\begin{array}{ccccc}
6 & 19 & 8 & 1 & 0 \\
6 & 18 & 7 & 2 & 1 \\
0 & 1 & 4 & 18 & 11
\end{array}\right] ; \quad R_{21}=\frac{1}{42}\left[\begin{array}{ccccc}
0 & 2 & 9 & 20 & 11 \\
0 & 3 & 9 & 18 & 12 \\
1 & 3 & 13 & 15 & 10
\end{array}\right] ; \quad R_{12}=\frac{1}{34}\left[\begin{array}{ccccc}
7 & 21 & 4 & 2 & 0 \\
22 & 8 & 4 & 0 & 0 \\
5 & 17 & 6 & 3 & 3 \\
2 & 7 & 11 & 8 & 6
\end{array}\right] ;
$$

$\operatorname{Jiayugua}\left(R_{2 i}\right)$

$>$ Comprehensive evaluation

Operator $\mathrm{M}(\circ, \oplus)$

$$
s_{k}=\min \left(1, \sum_{j=1}^{m} u_{j} r_{j k}\right), k=1,2, \ldots, n
$$

Atlanta:

$$
\begin{aligned}
\boldsymbol{B}_{\mathbf{1}}=\boldsymbol{A} \circ \boldsymbol{R}_{\mathbf{2}} & =\left(\begin{array}{l}
\mathrm{a}_{1}, \mathrm{a}_{2}, \mathrm{a}_{3}
\end{array}\right) \circ\left[\begin{array}{l}
A_{1} \circ R_{11} \\
A_{2} \circ R_{12} \\
A_{3} \circ R_{13}
\end{array}\right]=\left(\begin{array}{llllll}
0.6738 & 0.2255 & 0.1007
\end{array}\right) \circ\left(\begin{array}{ccccc}
0.1651 & 0.5179 & 0.2209 & 0.0684 & 0.0276 \\
0.1469 & 0.4712 & 0.1703 & 0.1081 & 0.1036 \\
0.2015 & 0.3513 & 0.2278 & 0.1709 & 0.0485
\end{array}\right) \\
& =\left(\begin{array}{lllll}
0.1744 & 0.4941 & 0.2102 & 0.0837 & 0.0376
\end{array}\right)
\end{aligned}
$$

The same as Jiayuguan.

Normalized

$$
\boldsymbol{B}=\frac{1}{\sum_{i=1}^{5} b_{i}}=\left(b_{1}, b_{2}, b_{3}, b_{4}, b_{5}\right) \triangleq\left(c_{1}, c_{2}, c_{3}, c_{4}, c_{5}\right)
$$

$$
\begin{aligned}
& \text { Results } \quad \boldsymbol{B}_{\mathbf{1}}=\left(\begin{array}{lllll}
0.1738 & 0.4925 & 0.2095 & 0.0834 & 0.0375
\end{array}\right) \text {; } \\
& \boldsymbol{B}_{2}=\left(\begin{array}{lllll}
0.0150 & 0.0692 & 0.2400 & 0.4358 & 0.2400
\end{array}\right) ;
\end{aligned}
$$

Results show, For a city, $c_{1} \%$ of the grids can get 10 points, $c_{2} \%$ of the grids can get 8 points, $c_{3} \%$ of the grids can get 6 points, $c_{4} \%$ of the grids can get 4 points, $c_{5} \%$ of the grids can get 2 points.

Let

$$
\boldsymbol{Y}=(10,8,6,4,2)^{\mathrm{T}}
$$

Calculate the score of two cities:

$$
\boldsymbol{Z}=\mathbf{1 0} c_{1}+8 c_{2}+6 c_{3}+4 c_{4}+2 c_{5}
$$


Table 2 Consistency check

\begin{tabular}{l|c}
\hline \hline Cities & Smart growth Coefficient $(\boldsymbol{Z})$ \\
\hline Atlanta $Z_{1}$ & 7.3436 \\
Jiayuguan $Z_{2}$ & 4.3668 \\
\hline
\end{tabular}

\section{Discussion}

Based on the plan developed, we raise the level of the indexes involved in the plan by one grade, while keeping the other indexes unchanged. Re-develop the judgment matrix and recalculate the new SGC. Analyze and compare.

The changes of SGC of the two cities are in ascending order plotted in the table below[7].

Table 3 SGC of Atlanta changing different indexes

\begin{tabular}{lccccc}
\hline \hline $\begin{array}{c}\text { Indexes } \\
\text { Improved }\end{array}$ & No change & $\begin{array}{c}\text { Workers/ } \\
\text { Residents } \\
\text { Balance } \\
\text { Index }\end{array}$ & $\begin{array}{c}\text { Natural } \\
\text { Population } \\
\text { Growth } \\
\text { Rate }\end{array}$ & $\begin{array}{c}\text { Mix Land } \\
\text { Uses Degree }\end{array}$ & $\begin{array}{c}\text { All the } \\
\text { three } \\
\text { indexes }\end{array}$ \\
\hline SGC (Z) & 7.2774 & 7.3302 & 7.3078 & 7.2958 & 7.3786 \\
\hline
\end{tabular}

Table 4 SGC of Jiayuguan changing different indexes

Table 5 Comparison of SGC

\section{Conclusion}

\begin{tabular}{cccccc}
\hline $\begin{array}{c}\text { Indexes } \\
\text { Improved }\end{array}$ & No change & $\begin{array}{c}\text { Per Capita } \\
\text { GDP }\end{array}$ & $\begin{array}{c}\text { Local } \\
\text { Financial } \\
\text { Revenue }\end{array}$ & $\begin{array}{c}\text { Natural } \\
\text { Population } \\
\text { Growth } \\
\text { Rate }\end{array}$ & $\begin{array}{c}\text { All the } \\
\text { three } \\
\text { indexes }\end{array}$ \\
\hline SGC (Z) & 4.3668 & 5.3160 & 4.6780 & 4.3936 & 6.2650 \\
\hline
\end{tabular}

After modeling and data analysis, the results showed that the Smart Growth Coefficient of Atlanta is $68.17 \%$ higher than Jiayuguan's. Atlanta is the capital and largest city of Georgia and it is an important aviation hub in the United States, where the airport passenger traffic is the world's first. The economy of Atlanta is well developed, so SGC is higher and more in line with the principle of smart growth. In contrast, the complex terrain and other factors are not conducive for Jiayuguan to open up. So its urbanization process develop slowly and is economically backward, so there is a big gap between smart growth.

All in all, the result of our study can provide a scientific basis for the development of the city in some way.

\section{Reference}

[1] Evaluating Smart Growth ,State and Local Policy Outcomes

http://www.lincolninst.edu/sites/default/files/pubfiles/evaluating-smart-growth-full.pdf

[2] Smart growth.http://baike.so.com/doc/1906776-2017569.html

[3] The strategy and case of United States "smart growth" and the application in China.

http://wenku.baidu.com/view/9e27be28cfc789eb172dc82c.html

[4] Multi-level Fuzzy Evaluation System

Bid Evaluation System of Construction Project Based on Multi-level Fuzzy Synthetic Evaluation

Model http://ieeexplore.ieee.org/stamp/stamp.jsp?arnumber=5593179

[5] The balance measurement and optimization of urban residential space

http://www.docin.com/p-730787838.html

[6] The chart of Income stratification

http://www.360doc.com/content/16/0627/02/32937398_571010831.html

[7]Mathematical and Computer Modelling

Volume 49, Issues 7-8, April 2009, Pages 1416-1426

http://www.sciencedirect.com/science/article/pii/S0895717709000272 